\title{
Mathematical model of the thalamo-cortical loop by dysfunction in schizophrenia
}

\author{
Nils Rosjat, Silvia Daun-Gruhn, Svitlana Popovych \\ From Twenty Second Annual Computational Neuroscience Meeting: CNS*2013 \\ Paris, France. 13-18 July 2013
}

Preceding experimental results suggest that disturbances of auditory information processing within the thalamocortical loop are a core issue relating schizophrenia [1]. Wide differences between schizophrenia patients and healthy controls were found in phase-locking of cortex EEG. We derive a phenomenological mathematical model based on coupled phase oscillators with continuous distributed frequencies to describe the neural activity of the thalamocortical loop. Concerning phaselocking effects observed we examine the influence of the bidirectional coupling strengths between the thalamic and the cortical area. We widen this approach to a model consisting of a thalamic area coupled to three cortical areas, each modeled by a set of nonidentical phase oscillators. At the investigation of our model we use Ott-Antonsen theory [2] and Pikovsky-Rosenblum reduction methods [3]. The results derived from our mathematical model coincide with the experimental data obtained by EEG measurements. The model provides that modifying the coupling strength from the thalamic region to a cortical region effects the duration of phase synchronization and while modifying the coupling back to the thalamic region affects the strength of synchronization in this cortical area. Thus it supports the view that the coupling between the thalamic region and cortical regions is the responsible mechanism for dysfunction of the thalamo-cortical loop in schizophrenia.

Published: 8 July 2013

\section{References}

1. Brockhaus-Dumke A, Müller R, Faigle U, Klosterkötter : Sensory gating revisited: Relation between brain oscillations and auditory evoked potentials in schizophrenia. Schizophrenia Research 2008, 99:238-249.

* Correspondence: rosjatn@uni-koeln.de

Emmy-Noether Research Group of Computational Biology, Department of Animal Physiology, University of Cologne, 50674 Cologne, Germany
2. Ott $\mathrm{E}$, Antonsen $\mathrm{T}$ : Low dimensional behavior of large systems of globally coupled oscillators. Chaos 2008, 18.

3. Pikovsky A, Rosenblum M: Dynamics of heterogeneous oscillator ensembles in terms of collective variables. Physica D 240:872-881.

doi:10.1186/1471-2202-14-S1-P320

Cite this article as: Rosjat et al:: Mathematical model of the thalamocortical loop by dysfunction in schizophrenia. BMC Neuroscience 201314 (Suppl 1):P320.
Submit your next manuscript to BioMed Central and take full advantage of:

- Convenient online submission

- Thorough peer review

- No space constraints or color figure charges

- Immediate publication on acceptance

- Inclusion in PubMed, CAS, Scopus and Google Scholar

- Research which is freely available for redistribution

\section{() Biomed Central}

C Biomed Central

(c) 2013 Rosjat et al; licensee BioMed Central Ltd. This is an Open Access article distributed under the terms of the Creative Commons Attribution License (http://creativecommons.org/licenses/by/2.0), which permits unrestricted use, distribution, and reproduction in any medium, provided the original work is properly cited. 